\title{
Effects of a long-term rearing system for deep-sea vesicomyid clams on host survival and endosymbiont retention
}

\author{
Tetsuro Ikuta $^{1} \cdot$ Makoto Sugimura $^{2} \cdot$ Suguru Nemoto $^{2}$ Yui Aoki ${ }^{1}$ Akihiro Tame ${ }^{3}$. \\ Masahiro Yamamoto $^{4}$ Masaki Saito $^{1}$ - Yoshiki Shimokawa ${ }^{5} \cdot$ Tetsuya Miwa $^{5,6,7}$. \\ Yukiko Nagai $^{1}$ - Takao Yoshida ${ }^{1} \cdot$ Katsunori Fujikura $^{1} \cdot$ Takashi Toyofuku $^{1}$
}

Received: 9 August 2017 / Accepted: 23 October 2017 / Published online: 14 November 2017

(C) The Author(s) 2017. This article is an open access publication

\begin{abstract}
Deep-sea vesicomyid clams, including the genus Phreagena, harbor obligate sulfur-oxidizing symbiotic bacteria in gill epithelial cells. Difficulty in maintaining Phreagena clams in rearing tanks has been a major obstacle to achieving a better understanding of their unique biology. To improve the method of rearing Phreagena clams, here we reared them in an artificial chemosynthetic aquarium and evaluated the effects of the aquarium system on long-term clam rearing. We compared the survival of clams reared in the artificial chemosynthetic tank with the survival of those in the normal tank, and analyzed the symbiont abundance using semi-quantification of fluorescent in situ hybridization
\end{abstract}

\footnotetext{
Tetsuro Ikuta

teikuta@jamstec.go.jp

Makoto Sugimura

sugimura@enosui.com

Suguru Nemoto

nemoto@enosui.com

Yui Aoki

yui.miyachi@gmail.com

Akihiro Tame

akihirot@jamstec.go.jp

Masahiro Yamamoto

myama@jamstec.go.jp

Masaki Saito

saito.masaki@jamstec.go.jp

Yoshiki Shimokawa

bz8cnrpq@i.softbank.jp

Tetsuya Miwa

miwat@jamstec.go.jp

Yukiko Nagai

nagai.y@jamstec.go.jp

Takao Yoshida

tyoshida@jamstec.go.jp
}

signals. Our results indicate that the artificial chemosynthetic aquarium system had specific effects on symbiont abundance and possibly on host survival. Furthermore, transmission electron microscopic observations of sulfur globules in the symbiont cells and expression analyses of the $d s r A$ gene of the symbiont indicated that stocked elemental sulfur could be consumed as an energy source to reduce sulfide shortages. We discuss the importance of higher and more stable sulfide concentrations and the proportions of available $\mathrm{O}_{2}$ and $\mathrm{CO}_{2}$ in driving appropriate metabolic functions of the symbiont and improving the survival of the clams.

Katsunori Fujikura

fujikura@jamstec.go.jp

Takashi Toyofuku

toyofuku@jamstec.go.jp

1 Department of Marine Biodiversity Research, Japan Agency

for Marine-Earth Science and Technology (JAMSTEC), 2-15

Natsushima, Yokosuka, Kanagawa 237-0061, Japan

2 Enoshima Aquarium, 2-19-1 Katasekaigan, Fujisawa, Kanagawa 251-0035, Japan

3 Marine Works Japan, Ltd., 3-54-1 Oppamahigashi, Yokosuka, Kanagawa 237-0063, Japan

4 Department of Subsurface Geobiological Analysis and Research, Japan Agency for Marine-Earth Science and Technology (JAMSTEC), 2-15 Natsushima, Yokosuka, Kanagawa 237-0061, Japan

5 Graduate School of Nanobioscience, Yokohama City University, 22-2 Seto, Kanazawa-ku, Yokohama 236-0027, Japan

6 Research and Development Center for Submarine Resources, Japan Agency for Marine-Earth Science and Technology (JAMSTEC), 2-15 Natsushima, Yokosuka, Kanagawa 237-0061, Japan 
Keywords Rearing aquarium - Chemosynthesis · Deep-sea clam $\cdot$ Phreagena $\cdot$ Sulfur oxidation $\cdot$ Symbiotic bacteria

\section{Introduction}

Various deep-sea animals establish unique symbiotic relationships with microbes such as chemoautotrophic bacteria, and these species subsist on organic matter produced by the symbionts. Deep-sea vesicomyid clams, including those of the genus Phreagena (formerly Calyptogena), are endemic and dominant members of deep-sea chemosynthesis-based communities [1]. These species harbor sulfur-oxidizing intracellular symbiotic bacteria (Gram-negative gammaproteobacteria) in their gill epithelial cells [2], and the clams depend on the symbionts for nutrition [3]. Recently, the robust and unique associations between Phreagena clams and their symbionts were revealed through genome sequencing of symbionts [2] and by studying the transmission mode of the symbionts [4].

The next step is to investigate these aspects using experimental biological approaches that employ live specimens. However, it is difficult to maintain Phreagena clams in rearing tanks [5]. Recently, Ohishi et al. reared $P$. okutanii and Phregena soyoae for over 150 days in a tank system at the Enoshima Aquarium that mimicked the deep-sea chemoautotrophic ecosystem [6], using decaying dog food as a sulfide source [5]. However, they reported that more than half of the clams died within 57 days after the onset of the rearing period [6]. Thus, there are still problems that must be addressed before the stable long-term rearing of Phreagena clams can be achieved. For example, the researchers observed a decrease in symbiotic bacteria in the gill epithelia during long-term rearing using the artificial chemosynthetic aquarium [6]. Because the symbionts are required by the host clams, it can be assumed that the observed decrease in symbiotic bacteria resulted in the deaths of the reared hosts. However, the causal relationship between the decrease in symbiont cells and the death of their hosts requires further assessment.

To address these issues, in the present study we reared Phreagena clams in the artificial chemosynthetic aquarium system at the Enoshima Aquarium, as well as in two reference tanks with sediment only or without sediment. We then compared the survival of the clams among the three tanks. We sampled the clams from the three tanks

Marine Technology and Engineering Center (MARITEC), Japan Agency for Marine-Earth Science and Technology (JAMSTEC), 2-15 Natsushima, Yokosuka, Kanagawa 237-0061, Japan at certain intervals, and observed the abundance of the symbiotic bacteria in the gill epithelia by in situ hybridization that targeted symbiont $16 \mathrm{~S}$ rRNA. Furthermore, we observed the sulfur globules-assumed to be sites of elemental sulfur storage $[4,7,8]$-in the symbiont cells and investigated the expression of one of the key enzymes potentially responsible for sulfur metabolism in the symbiont. After presenting the results below, we discuss the issues that need to be addressed to achieve more stable rearing of Phreagena clams.

\section{Materials and methods}

\section{Animal collection}

All Phreagena clams were collected using the ROV HyperDolphin, operated by the R/V Natsushima of the Japan Agency of Marine-Earth Science and Technology. Sampling site was Off Hatsushima Island seep site in Sagami Bay at depths of $860 \mathrm{~m}\left(35^{\circ} 00.948^{\prime} \mathrm{N}, 139^{\circ} 13.310^{\prime} \mathrm{E}\right.$, Dive\#1641), $949 \mathrm{~m}\left(35^{\circ} 00.924^{\prime} \mathrm{N}, 139^{\circ} 13.426^{\prime} \mathrm{E}\right.$, Dive\#1643) and $858 \mathrm{~m}\left(35^{\circ} 00.966^{\prime} \mathrm{N}, 139^{\circ} 13.329^{\prime} \mathrm{E}\right.$, Dive\#1644) during cruise NT14-05 (April 2-8, 2014). Clams were collected in a box $[40$ (width) $\times 40$ (length) $\times 30$ (height) $\mathrm{cm}$ ] with a lid. The temperature of the surface seawater upon recovery was between 15.6 and $16.5^{\circ} \mathrm{C}$. Some of the collected clams were immediately dissected on board, and their gills and feet were excised using a disposable scalpel. For fluorescent in situ hybridization (FISH) analysis, the gills were fixed in $4 \%$ paraformaldehyde in $1 \times$ phosphate-buffered saline (PBS) for $16 \mathrm{~h}$ at $4{ }^{\circ} \mathrm{C}$, followed by stepwise dehydration in an ethanol series. The fixed samples were kept in $100 \%$ ethanol at $-30{ }^{\circ} \mathrm{C}$ until use. For transmission electron microscope (TEM) observations, the gills were fixed in $2.5 \%$ glutaraldehyde in seawater filtered with a $0.2-\mu \mathrm{m}$ filter unit (Nalgene, Rochester, NY, USA) (filtered seawater, FSW) at $4{ }^{\circ} \mathrm{C}$. For RNA extraction, the gills were placed into RNAlater RNA Stabilization Solution (Qiagen, Hilden, Germany), incubated for $16 \mathrm{~h}$ at $4{ }^{\circ} \mathrm{C}$, and stored at $-80^{\circ} \mathrm{C}$. The feet were frozen in liquid nitrogen and stored at $-80^{\circ} \mathrm{C}$ for DNA extraction. The other collected clams were kept in shipboard tanks equipped with a protein skimmer at $3.9^{\circ} \mathrm{C}$ water temperature on average, and approximately $50 \%$ of the seawater in the tanks was changed every 1-2 days during the NT14-05 cruise. After the cruise, the clams were individually packaged in a plastic bag with seawater maintained at $2.8^{\circ} \mathrm{C}$ on average, and were immediately transported to the Enoshima Aquarium, Kanagawa, Japan. At the collection site, two morphologically similar sibling species, $P$. okutanii and $P$. soyoae, are known to form a mixed colony [9]. In the present study, we identified only the dissected clams, all of which were identified as $P$. okutanii, by the multiplex-PCR 
method described previously [10], using DNA extracted from the foot with the DNeasy Blood and Tissue Kit (Qiagen) as a template.

\section{Rearing tanks for Phreagena clams and animal sampling}

In the artificial chemosynthetic aquarium at the Enoshima Aquarium, dog food (Vita-One, Nippon Pet Food, Tokyo, Japan) was buried in the sediment from Ariake Bay, Japan for sulfide generation as described previously (Fig. 1) [5, 6] 65 days before the onset of rearing. After the cruise, 29 individual clams were transferred to the artificial chemosynthetic tank (tank A). During the rearing period, dog food was not added again, and the sediment in the tank was not mixed. As a reference, 30 clams were kept in a tank [60 (width) $\times 45$ (length) $\times 45$ (depth) $\mathrm{cm}$ ] filled with $121.5 \mathrm{~L}$ of seawater, where the bottom was covered with sediment from Ariake Bay but there was no dog food (tank B). As another reference, the other 30 clams were kept in another tank [60 (width) $\times 45$ (length) $\times 45$ (depth) $\mathrm{cm}]$ without sediment or dog food (tank C). The whole tank system was maintained at a seawater temperature of $4.06{ }^{\circ} \mathrm{C}$ and an average $\mathrm{pH}$ of 7.45 . Tank A was exhibited to the public at the Enoshima Aquarium. Live clams were randomly selected from each tank, including one live clam each on days 7,15 , and 30 of rearing and three live clams each on days 42 and 91 . The samples were then dissected and immediately fixed for FISH analysis and RNA extraction or frozen for species identification as described above. Additionally, the gills of the clams dissected on day 91 were also fixed for TEM observation. When a dead clam was found during rearing, it was immediately removed from the tank and fixed in $4 \%$ formaldehyde in seawater. Accordingly, its survival time was recorded and, based on this, the survival rates of the clams were calculated with a Kaplan-Meier analysis in which nine individuals sampled from each of the three tanks throughout the rearing period were treated as censors. Statistical analysis was performed using Microsoft Office Excel for Mac 2011 (Microsoft, Redmond, WA, USA), in which $P$ values were calculated via the log-rank test at the 5\% significance level.
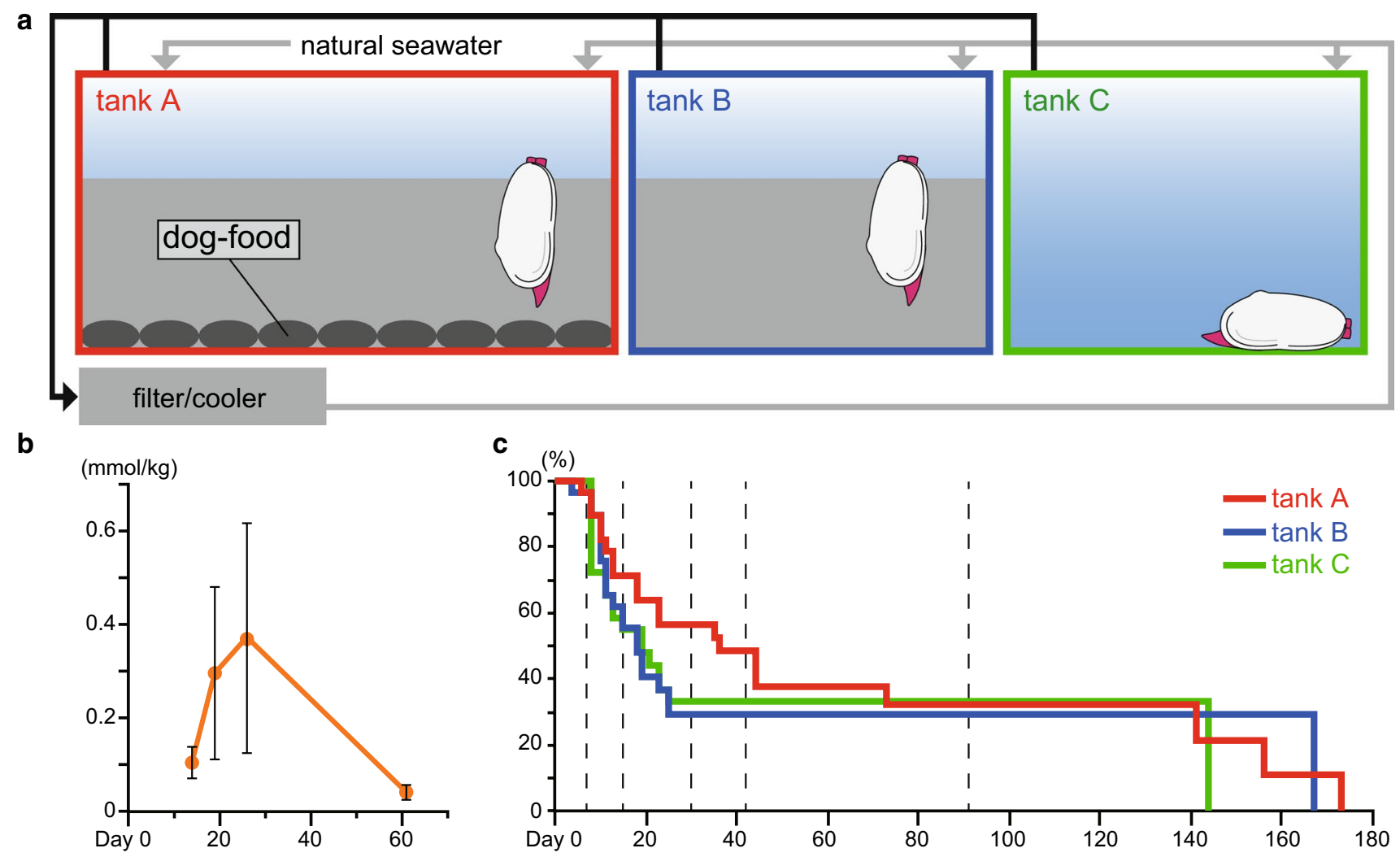

Fig. 1 Aquarium tank setup and survival rates of reared clams. a Schematic representation of the setup of tank A with dog food buried in sediment, tank B with sediment but without dog food, and tank C without sediment or dog food. b Average concentrations of sulfide in the sediment of tank A at a depth of $15-30 \mathrm{~cm}$ during the rearing period. Error bars indicate standard deviations. c Survival rates (\%) of clams reared in each tank. Dotted lines indicate the days on which clams were sampled 


\section{Investigation of the chemical composition of seawater in the habitat and aquarium}

Sediment samples of the natural habitat were recovered from the edge of a large Phreagena colony to measure the $\mathrm{pH}$ and total alkalinity (TA) of interstitial water using push corers with plastic tubes ( $82 \mathrm{~mm}$ internal diameter). Sampling sites was the Off Hatsushima Island seep site in Sagami Bay at depths of $855 \mathrm{~m}\left(35^{\circ} 00.966^{\prime} \mathrm{N}, 139^{\circ} 13.322^{\prime} \mathrm{E}\right.$, Dive\#1644) during cruise NT14-05 (April 2-8, 2014). The pH of the interstitial water of the sediment was measured using an optical fiber $\mathrm{pH}$ meter ( $\mathrm{pH}-1$ micro, PreSens Precision Sensing, Regensburg, Germany) on board. Sediment samples were centrifuged in 50-ml tubes for $20 \mathrm{~min}$ at $2800 \mathrm{rpm}$ to extract interstitial water. The extracted waters were poisoned with mercury(II) chloride to prevent changes in the levels of dissolved inorganic carbon due to microbial activity. TA was determined using a $\mathrm{pH}$ method $[11,12]$ at the laboratory of JAMSTEC after the cruise. The $\mathrm{CO}_{2}$ concentration in the seawater was estimated using the CO2SYS software package [13] after determining $\mathrm{pH}$ and TA.

At the aquarium, the sulfide concentration was measured in seawater and sediment using the voltammetry method [14]. A potentiostat system (HZ-3000: Hokuto-Denko, Atsugi, Japan) and a working 35-cm microelectrode supported by a glass tube ( $4 \mathrm{~mm}$ diameter) were used for voltammetry measurements and analyses. Measurements were conducted every $5 \mathrm{~cm}$ down to a depth of $30 \mathrm{~cm}$ from the surface at six fixed points in the aquarium on days 14,19 , 26 , and 61 of rearing. The aquatic $\mathrm{CO}_{2}$ concentration was estimated from the measured $\mathrm{pH}$ and TA of the bottom water from tank $\mathrm{A}$. The $\mathrm{pH}$ was measured using a conventional $\mathrm{pH}$ meter with a glass electrode (5-star Plus, Thermo Scientific Orion, Waltham, MA, USA), and TA was determined by a $\mathrm{pH}$ method $[11,12]$. The $\mathrm{CO}_{2}$ concentration was estimated using the CO2SYS software package [13] with $\mathrm{pH}$ and TA.

\section{FISH and semi-quantitative analysis of fluorescent signals}

Generally, quantitative PCR (qPCR) that counts DNA molecules of the rRNA gene is used to quantify endosymbiont abundance in marine invertebrates, including bivalves [15]. However, the symbiont of $P$. okutanii was recently found to exhibit polyploidy [4]. Because the genomic copy number of the gill symbionts of $P$. okutanii under starvation conditions is unknown, quantification of rRNA genes via qPCR may not necessarily lead to reliable results regarding symbiont abundance. Therefore, in this study, we employed a FISH analysis, which was previously found to be applicable for estimating the amount of endosymbionts [16]. Our FISH analyses were conducted as described previously [16], with the following modifications. The fixed gill was embedded in paraffin and sliced into $4-\mu \mathrm{m}$ transverse sections. The sections were dewaxed and subjected to hybridization at $46{ }^{\circ} \mathrm{C}$ using a solution containing $20 \%$ formamide, $0.9 \mathrm{M} \mathrm{NaCl}$, $20 \mathrm{mM}$ Tris- $\mathrm{HCl} \mathrm{pH} 7.5,5 \mathrm{mM}$ EDTA, 0.01\% SDS, and $0.5 \mu \mathrm{M}$ FITC-labeled probe Cok 16S_1 (5'-AGCTTCGCC ACTAAAGGGTACCCCC-3'), which was designed to be specific to the $16 \mathrm{~S}$ rRNA of the $P$. okutanii symbiont [17]. After hybridization, excess probe was washed away twice in a wash solution containing $0.225 \mathrm{M} \mathrm{NaCl}, 20 \mathrm{mM}$ Tris$\mathrm{HCl} \mathrm{pH} 7.5,5 \mathrm{mM}$ EDTA, and $0.01 \% \mathrm{SDS}$ for $30 \mathrm{~min}$ at $48{ }^{\circ} \mathrm{C}$, and the sections were then mounted in Vectashield with DAPI (Vector Laboratories, Burlingame, CA, USA).

FISH images were captured using a Nikon A1RMP confocal scanning system (Nikon Instech, Tokyo, Japan). For semi-quantitative analysis of the fluorescent signals, all of the micrographs were obtained using the same settings. The area of the gill filament was manually traced in the resulting DIC image using Nikon NIS-Elements software (Nikon Instech). The integrated fluorescent intensity, which indicates the number and the activity of symbiont cells within the area of the gill filament, was then calculated using the Nikon NIS-Elements software and expressed as the value per area, as described previously [16]. Three randomly selected gill filaments in a scanned field of three randomly selected paraffin sections per individual specimen were analyzed. Statistical analysis was performed using Microsoft Office Excel for Mac 2011, and $P$ values were calculated using Student's or Welch's $t$ tests at the $1 \%$ significance level.

\section{TEM observations}

For gill tissue sections, the fixed gills were prepared as described previously [4]. Briefly, pieces of the gills were post-fixed with $2.0 \%$ osmium tetroxide dissolved in filtered artificial seawater (FASW) for $2 \mathrm{~h}$ at $4{ }^{\circ} \mathrm{C}$. After washing with an $8.0 \%$ sucrose aqueous solution, conductive staining was performed by incubation in $0.5 \%$ thiocarbohydrazide (Thermo Fisher Scientific, Waltham, MA, USA) aqueous solution for $30 \mathrm{~min}$ and $1.0 \%$ osmium tetraoxide aqueous solution for $1 \mathrm{~h}$ at $4{ }^{\circ} \mathrm{C}$. The samples were dehydrated in a graded ethanol series and then embedded in Epon 812 (TAAB, Aldermaston, UK). Ultrathin sections (60 nm thick) were cut with a diamond knife on an Ultracut S ultramicrotome (Leica Microsystems, Wetzlar, Germany) stained with $2.0 \%$ uranyl acetate and $2.0 \%$ lead citrate solutions, and observed using a Tecnai G2 20 transmission electron microscope (FEI, Hillsboro, OR, USA) operated at $120 \mathrm{kV}$.

\section{Quantitative real-time PCR (qPCR)}

Total RNA was isolated from the gills of clams that were freshly collected or reared in tanks A and B using the classical guanidine thiocyanate method with pelleting through 
cesium chloride. The RNA samples were treated with recombinant DNase I (Takara, Shiga, Japan) at $37{ }^{\circ} \mathrm{C}$ for $30 \mathrm{~min}$, and then purified via phenol-chloroform extraction and ethanol precipitation. For each individual, cDNA was synthesized using a PrimeScript II 1st strand cDNA Synthesis Kit (Takara) with $1 \mu \mathrm{g}$ of total RNA in a volume of $20 \mu \mathrm{L}$, and water was added to obtain a volume of $100 \mu \mathrm{L}$ after the reaction. Reverse transcriptase was omitted (negative RT - control) for the negative control in the qPCR analysis. Primers for $d s r A$ and the $16 S r R N A$ gene (for normalization) were designed using Primer Express software v.3.0 (Thermo Fisher Scientific) on the basis of the genomic sequence of the $P$. okutanii symbiont (accession no. AP009247, [2]) to amplify 100-bp fragments. The qPCR primers used in this study were as follows: dsrA-qF, 5'-TTG TGTCGGTGCTTCACGTT-3'; dsrA-qR, 5'-TGCTGGACG ATGCATATCATC-3'; 16S-qF, 5'-ACAAGCGGTGGAGCA TGTG-3'; and 16S-qR, 5'-CCCGAAGGCACCAATCTA TC-3'. The qPCR analysis was performed on an Applied Biosystems 7300 Real-Time PCR System (Thermo Fisher Scientific) in $20-\mu \mathrm{L}$ reaction mixtures containing $10 \mu \mathrm{L}$ of PowerUp SYBR Green PCR Master Mix (Thermo Fisher Scientific) and each primer at $0.6 \mu \mathrm{M}$ along with $1 \mu \mathrm{L}$ of the cDNA template. The reaction conditions were as follows: 2 min at $50{ }^{\circ} \mathrm{C} ; 2$ min at $95^{\circ} \mathrm{C} ; 40$ cycles of $95^{\circ} \mathrm{C}$ for $15 \mathrm{~s}$; $60{ }^{\circ} \mathrm{C}$ for $1 \mathrm{~min}$; a ramped melting step was performed from $60{ }^{\circ} \mathrm{C}$ to $95{ }^{\circ} \mathrm{C}$ to confirm the specificity of the amplified PCR products. All assays were performed in triplicate, and no-template controls (NTC) containing $1 \mu \mathrm{L}$ of $\mathrm{H}_{2} \mathrm{O}$ rather than cDNA as well as negative RT- controls (see above) were run with every assay to determine the specificity of the target amplification. Due to the limited number of wells in our qPCR device, we only used samples from tank B as a reference. Quantification analysis was performed using SDS v.1.3.1 software (Thermo Fisher Scientific), and the threshold cycle $(\mathrm{Cq})$ was automatically determined for each gene. The expression levels of the $d s r A$ gene were calculated using the $2^{-\Delta \Delta \mathrm{Cq}}$ method [18] in comparison with those of standard control sample from a freshly collected clam.

\section{Results}

\section{Chemical compositions of the seawater in the habitat and aquarium $(\operatorname{tank} \mathbf{A})$}

Information about the chemical compositions of the seawater in the habitat and aquarium (tank A), based on previous reports or the present study, is shown in Fig. 1b and Table 1. Throughout the rearing period, the concentration of sulfide in the seawater above the clams in tank A was $<0.00037 \mathrm{mmol} / \mathrm{kg}$ (i.e., below the detection limit; Table 1). In the sediment at a depth of $15-30 \mathrm{~cm}$, the average sulfide concentration was relatively low on day 14 (when undetectable, the concentration was defined as 0 ; the average $\pm \mathrm{SD}$ was $0.105 \pm 0.035 \mathrm{mmol} / \mathrm{kg}$ ) but increased to the maximum $(0.374 \pm 0.248 \mathrm{mmol} / \mathrm{kg})$ on day 26 and decreased to the minimum $(0.040 \pm 0.017 \mathrm{mmol} / \mathrm{kg})$ on day 61 (Fig. 1b). Throughout the rearing period, the concentration ranged from undetectable to $0.705 \mathrm{mmol} / \mathrm{kg}$ (detected on day 61 at a depth of $25 \mathrm{~cm}$ ), and the average $\pm \mathrm{SD}$ was $0.204 \pm 0.205 \mathrm{mmol} / \mathrm{kg}$ (Table 1$)$.

\section{Survival rates of clams in rearing tanks}

The survival rates of Phreagena clams in the tanks (A-C) throughout the rearing period are shown in Fig. 1c. In tank A, no clams died within the first 5 days of rearing. From 6 to 30 days after the onset of rearing, 12 clams died, and the longest survival period was 173 days. The median survival time was estimated to be 36 days. In tank B, no clams died within the first 3 days of rearing. From 4 to 30 days after the onset of rearing, 20 clams died, and the longest survival period was 167 days. The median survival time was estimated to be 18 days. In tank $\mathrm{C}$, no clams died within the first 7 days of rearing. From 8 to 30 days after the onset of rearing, 19 clams died, and the longest survival period was 144 days. The median survival time was estimated to be 19 days. Therefore, median survival time was longest in tank-A. In addition, the survival rate in tank A 30 days after
Table 1 Chemical composition of seawater in the habitat and aquarium (tank A)

\begin{tabular}{lllll}
\hline & $\mathrm{pH}$ & $\mathrm{DO}(\mu \mathrm{M})$ & $\mathrm{H}_{2} \mathrm{~S}(\mathrm{mmol} / \mathrm{kg})$ & $\mathrm{CO}_{2}(\mu \mathrm{mol} / \mathrm{kg})$ \\
\hline Habitat (Sagami Bay) & & & & \\
Seawater above the colony & 7.7 & 44.4 & $\mathrm{ND}$ & $46^{\mathrm{a}}$ \\
& {$[27]$} & {$[26]$} & {$[29]$} & 396 \\
Sediment & 7.79 & 0 & $<13.8$ & \\
Aquarium (tank A) & & {$[30]$} & {$[31]$} & 108 \\
Seawater above the clams & 7.45 & 310 & $\mathrm{ND}$ & $\mathrm{NA}$ \\
Sediment & & {$[6]$} & & \\
\hline
\end{tabular}

ND not detected, $N A$ not analyzed

${ }^{\mathrm{a}}$ Calculated using data in [27] and [32] 
the onset of rearing was almost double that of the reference tanks. However, no statistically significant differences were detected among the survival rates in the three tanks throughout the rearing period, or those within 30 days after the onset of rearing.

\section{Symbiont abundance in the gills of reared clams}

In the FISH analysis, intense hybridization signals were detected in the inner area of the gill filament of each freshly collected clam, as described previously $[19,6]$ (Fig. 2a). Similarly, intense signals were detected in the gills of clams reared for $7,15,30$, and 42 days in all three tanks, regardless of the presence of sediment or dog food (Fig. 2b). In contrast, the gill bacteriocytes in the three dissected clams reared in tank A for 91 days appeared thinner than those of freshly collected clams, and the area of the fluorescent signal decreased (Fig. 2b). Furthermore, in dissected clams reared in tanks B and C for 91 days,
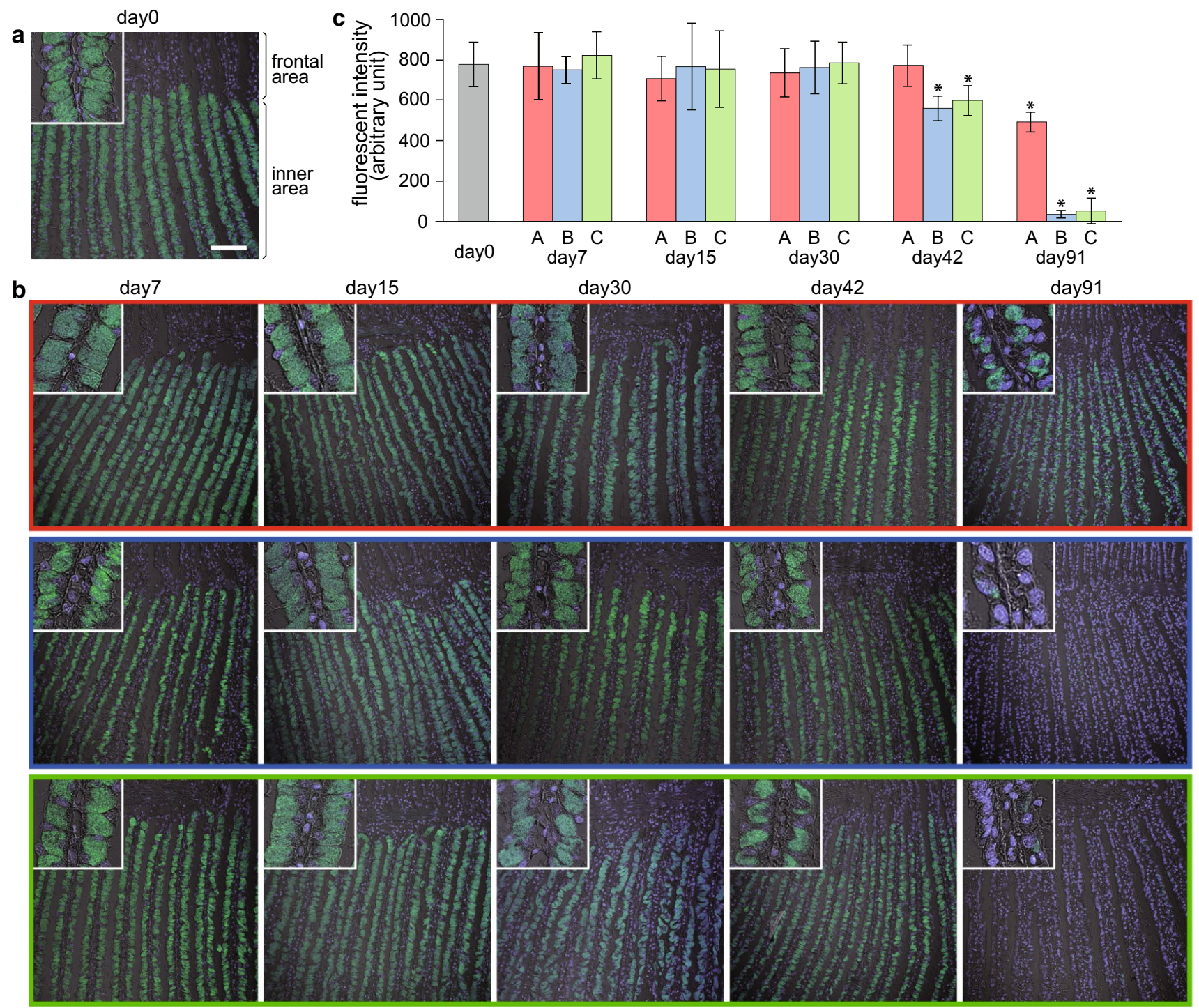

Fig. 2 Detection and semi-quantification of symbiotic bacteria in the gills of clams reared in tanks using FISH analyses. a and b Cross-sections of the gill filaments of clams hybridized with the FITC-labeled Cok 16S_1 probe. FISH signals were merged with DAPI signals and DIC images. For all panels, the asymbiotic frontal area is toward the top. Scale bar: $100 \mu \mathrm{m}$ (applicable to all panels). Insets show highermagnification images. a The gill of a freshly collected clam (day 0). Symbiont signals were detected in the bacteriocytes in the inner area. b The gills of clams reared in tank A (upper panels in a red box), tank B (middle panels in a blue box), and tank C (lower panels in a green box). Rearing periods are indicated at the top. $\mathbf{c}$ Abundances of symbiont cells in the gills of clams reared in tank A (red bars), tank B (blue bars), and tank C (green bars), which were estimated from the fluorescent intensities of the FISH signals. The gray bar indicates a freshly collected clam (day 0). Asterisks indicate statistically significant differences relative to the freshly collected clam, and error bars indicate the standard deviation 
the gill epithelia markedly shrunk, and weak fluorescent signals were sparsely detected in small spots (Fig. 2b).

In the semi-quantitative analyses of the fluorescent signals, there were no significant differences in fluorescent intensity between the freshly collected clam and the clams reared for 7, 15, and 30 days in all three tanks, regardless of the presence of sediment or dog food (Fig. 2c). However, on day 42 , the fluorescence intensities of the clams reared in tanks B and C were lower than those of the clam in tank A and those of the freshly collected clam, whereas no difference was found between the freshly collected clam and the clam reared in tank A (Fig. 2c). On day 91, the fluorescence intensities of the clam reared in tank A were lower than those of the freshly collected clam. Moreover, in the clams reared in tanks $\mathrm{B}$ and $\mathrm{C}$, the fluorescence signal from the symbiont cells decreased drastically (Fig. 2c).
Additionally, we observed the gills of the clams using TEM. In the gill bacteriocytes of freshly collected clams, we detected numerous symbiont cells in which electrontransparent vesicles were frequently observed ( $81 \%$ of the 63 symbiont cells counted), as previously noted [4] (Fig. 3a). The average vesicle size was $450($ s.d. $=163 ; n=20) \times 359$ (s.d. $=125 ; n=20) \mathrm{nm}$. In the clams reared in tank A for 91 days, several (but apparently fewer than in the freshly collected clams) symbiont-like structures were observed in the gill epithelial cells (Fig. 3a). Electron-transparent vesicles were occasionally detected (19\% of the 54 symbiont cells counted), but they appeared smaller than those in the symbiont cells of freshly collected clams (yellow arrowhead in the second left lower panel of Fig. 3a). The average vesicle size was 163 (s.d. $=50 ; n=20) \times 133$ (s.d. $=42 ; n=20) \mathrm{nm}$. In the clams reared in tanks $\mathrm{B}$ and $\mathrm{C}$, symbiont-like structures

\section{a}
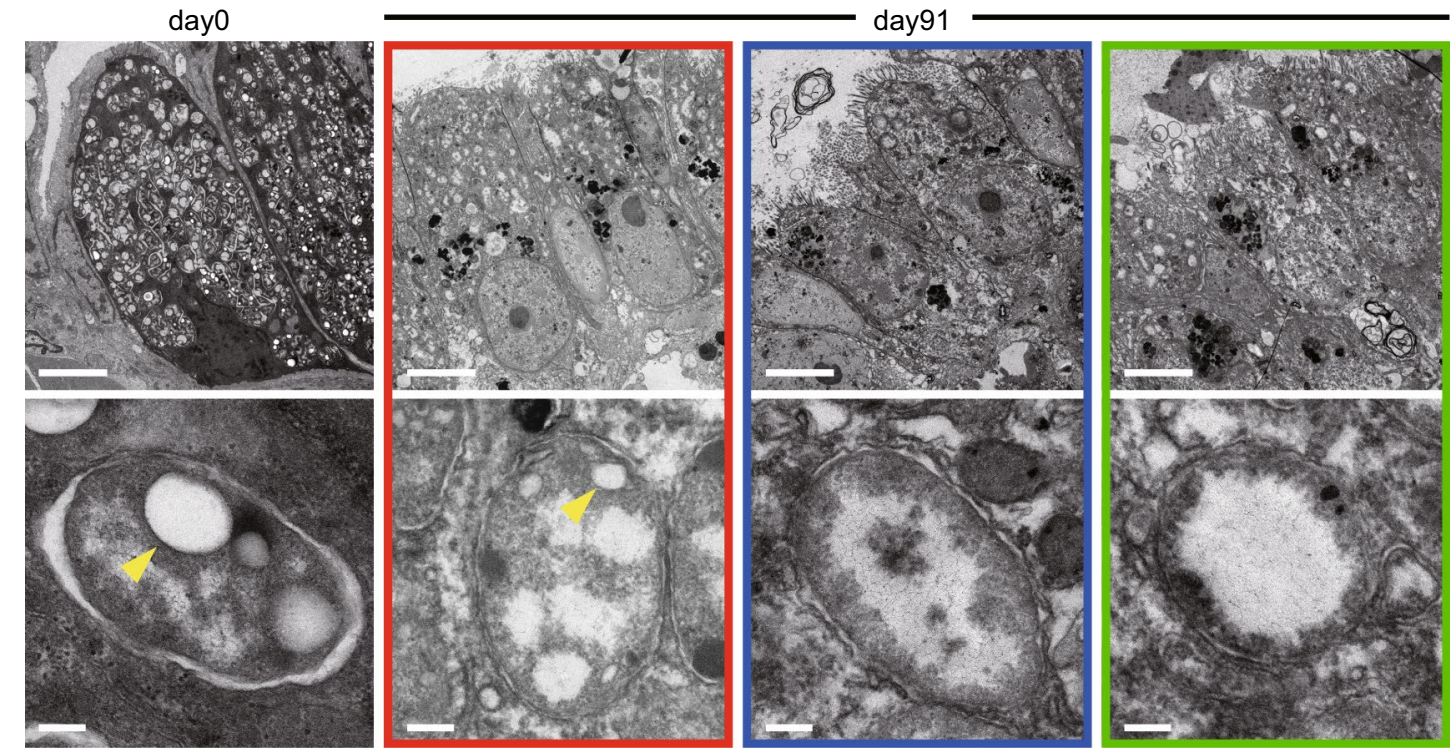

b

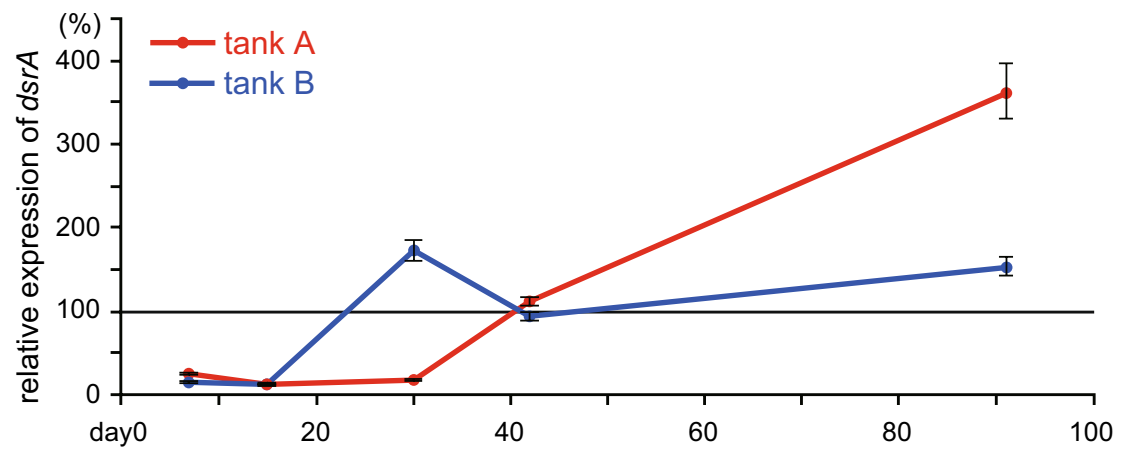

Fig. 3 Consumption of elemental sulfur stocked in symbiont cells during the long-term rearing period. a TEM images of gill bacteriocytes and symbiont cells in a freshly collected clam (left panels), and those reared for 91 days in tank A (second left panels in a red box), tank B (second right panels in a blue box), and tank C (right panels in a green box). Upper panels show bacteriocytes, and lower panels show symbiont cells at high magnification. Arrowheads indicate sulfur globules. Scale bars: $5 \mu \mathrm{m}$ in upper panels and $200 \mathrm{~nm}$ in lower panels. b Relative expression changes of the symbiont $d s r A$ gene in clams reared in tanks $\mathrm{A}$ and $\mathrm{B}$ (obtained using the $2^{-\Delta \Delta \mathrm{Cq}}$ method) in comparison to the freshly collected clam. Error bars represent the range of relative expression 
were rarely observed in gill epithelial cells, which looked thinner than the bacteriocytes of freshly collected clams (Fig. 3a). Electron-transparent vesicles were not detected in the symbiont-like structures (Fig. 3a).

\section{Expression of the $d s r A$ gene that encodes an enzyme potentially involved in the oxidation of stored sulfur}

Electron-transparent vesicles, which were observed in the gill symbiont cells of $P$. okutanii, are assumed to be sites of elemental sulfur storage [4]. Similar electron transparentvesicles called sulfur globules have been broadly detected in thiotrophic bacteria, and the stocked elemental sulfur can serve as a temporary energy reservoir [20]. In the purple sulfur bacterium Allochromatium vinosum, the enzyme responsible for the oxidation of sulfur stored in the globule is known to be dissimilatory sulfite reductase (Dsr) [20, 7]. In the present study, we investigated the expression of $d s r A$, which encodes a subunit of the heterodimer protein DsrAB [21], in the P. okutanii symbiont in clams reared in tanks $\mathrm{A}$ and $\mathrm{B}$. In the clams reared in tank A, the $d s r A$ transcript levels decreased to 26,11 , and $19 \%$ of the levels seen for the freshly collected clam on days 7,15 , and 30 , respectively. The levels had recovered (111\%) by day 42 , and expression of $d s r A$ was then upregulated to $362 \%$ on day 91 (Fig. 3b). In the clams reared in tank $\mathrm{B}$, the $d s r A$ transcript levels decreased to 16 and $11 \%$ on days 7 and 15 , respectively, but they increased or recovered to 173,93 , and $153 \%$ on days 30, 42, and 91, respectively (Fig. 3b).

\section{Discussion}

\section{Effectiveness of the artificial chemosynthetic aquarium system for the long-term rearing of Phreagena clams}

Although Phreagena clams can be reared in aquarium tanks for over 100 days [5, 6], to our knowledge, this is the first detailed multidisciplinary evaluation of the effects of the artificial chemosynthetic aquarium system on the survival of host clams and their symbionts. Our results indicate that there were no statistically significant differences among the host survival rates of the three tanks during the rearing period. Moreover, massive mortality of the clams occurred within 30 days after the onset of rearing in all three tanks, and the longest clam survival times in the three tanks were almost the same (i.e., approximately 150 days, Fig. 1c). Therefore, no major differences were detected among the tanks with regard to survival rates and survival times of the host clams. We speculate that improvements in the methods of handling and care of clams on the ship as well as the transportation of the clams to the aquarium led to longer survival times in recent studies $[5,6]$ as well as the present study. Furthermore, the high input number of clams reared in recent studies (approximately 100 individuals in [6] and the present study) may have stochastically resulted in longer survival records. However, it should not be overlooked that the median survival time was longest in tank A, and the survival rate in tank A 30 days after the onset of rearing was almost double that in the reference tanks. This suggests that our artificial chemosynthetic aquarium system might have some positive effects on the survival of the host, at least in the initial period of rearing.

In the semi-quantitative analysis of FISH signals, the fluorescent intensities of the clam reared in tank A with dog food in the sediment were higher than those observed in tanks B and C 42 and 91 days after the onset of rearing (Fig. 2). Thus, our results showed that our artificial chemosynthetic aquarium system has a positive effect on the abundance of the symbiont during long-term rearing. In addition, these results also indicate that the massive mortality of the host clams that occurred within 30 days after the onset of rearing was not necessarily caused by a decrease in symbiont cells.

\section{Consumption of elemental sulfur stocked in symbiont cells}

Electron-transparent vesicles have been broadly detected in thiotrophic bacteria, and are thought to be the sites of elemental sulfur storage (i.e., sulfur globules) [7]. Previously, Ohishi et al. observed decreased elemental sulfur in the gills of Phreagena clams during long-term rearing, and this may have resulted from a shortage of sulfide in the tank [6]. In our TEM observations of gill bacteriocytes of clams reared for 91 days, electron-transparent vesicles were occasionally detected in symbiont cells from tank A, but they were smaller than those in freshly collected clams. In contrast, such vesicles were never detected in symbiont cells from tanks B and C (Fig. 3a). These results suggest that the sulfide supplied in tank A would have specific effects on the sulfur metabolism of the symbiont during long-term rearing.

The formation and degradation of sulfur globules have been well studied in the purple sulfur bacterium A. vinosum, and the best-studied enzyme system responsible for the oxidation of sulfur stored in the globules of this species is the Dsr system. As well as being used to derive energy using elemental sulfur, the Dsr system is also the exclusive pathway used to oxidize sulfide to sulfite in thiotrophic bacteria lacking soxC and soxD genes (Sox-CD), such as the P. okutanii symbiont $[22,2]$. In this study, we investigated the expression of $d s r A$ in the Phreagena symbiont in clams reared in tanks $\mathrm{A}$ and B using qPCR. In the clams reared in tank A, $d s r A$ expression levels were low (11-26\%) in comparison to the freshly collected clam until day 30 . Upregulation of $d s r A$ was detected after day 42, and expression peaked on day 91 (Fig. 3b). A previous study using A. vinosum showed that the 
sulfide in the culture medium was initially metabolized and that sulfur globules were formed. Then, after the sulfide in the medium was completely oxidized to elemental sulfur, the expression of $d s r A$ was enhanced and the stored sulfur was further metabolized to sulfate [23]. Similarly, in the present study, sulfide derived from dog food in tank A would have initially been oxidized to elemental sulfur without the Dsr system. The concentration of sulfide then decreased to its minimum on day 61 . Under such conditions, the oxidation of sulfide to sulfate would have predominated, and stocked elemental sulfur would have been consumed by the Dsr system. This seems to be consistent not only with the maximum expression level of $d s r A$ in the clam reared in tank A for 91 days but also with our TEM observations, as rarer and smaller electron-transparent vesicles were detected in the symbiont cells in the clams reared in tank A for 91 days (Fig. 3a), indicating that stocked elemental sulfur was being consumed. The lack of sulfide and the extreme starvation conditions in tank B may have triggered the Dsr system and induced the utilization of stocked elemental sulfur earlier than in tank A. Consistently, no transparent vesicles were detected in the symbiont cells of the clams reared for 91 days in tank B (Fig. 3a), which may indicate that the stocked elemental sulfur was completely consumed. Exhaustion of the stocked elemental sulfur probably affected the abundance of the symbiont.

\section{Improvements required for more stable $P$. okutanii rearing}

In this study, the concentration of sulfide in tank A was unstable (Fig. 1b). This may have affected the sulfur metabolism and abundance of the symbiont during long-term rearing, as discussed above. The most likely explanation for this instability is that the higher concentrations of sulfide observed 19 and 26 days after the onset of rearing arose because the peak decomposition of dog food occurred during this period, and the subsequent decrease in the concentration of sulfide may have been due to the consumption of organic matter in the dog food. Alternatively, we speculate that the increase and decrease in the sulfide concentration are related to the agitation of the sediment by the burrowing clams, as this may have promoted the inflow of sulfate in the sediment and accordingly affected the activity of sulfur-reducing bacteria responsible for sulfide production. Considering these points, occasional artificial agitation of the sediment in the tank or the addition of dog food during rearing may help to maintain higher and more stable concentrations of sulfide and eventually improve at least the endosymbiont retention and possibly the survival of the host clams.

In our study, massive mortality of the host occurred in all three tanks even before the period in which a decrease in symbiotic bacteria was observed (i.e., before day 42).
Dead clams in the tanks could not be used for analyses because their freshness was lost by the time of discovery. Therefore, we cannot completely exclude the possibility that only sampled clams maintained their symbionts, whereas dead clams lost their symbionts. However, this appears to be unlikely, as three clams were randomly sampled from all three tanks during this period (nine clams in total), and there were no signs of a decreased number of symbiont cells in any of the clams. It is possible that the clams died because of their sensitivity to environmental changes, including pressure and temperature changes.

Alternatively, even though energy was likely provided by the oxidation of reduced sulfur compounds derived from the dog food or from stocked elemental sulfur, carbon fixation might have been impeded because of the imperfect catalytic function of ribulose 1,5-bisphosphate carboxylase/oxygenase (RubisCO) [24]. The symbiont of P. okutanii has the form II RubisCO gene ( $c b b M)$ in the genome for carbon fixation [2]. It has generally been concluded that form II RubisCO enzymes are adapted for functioning in low- $\mathrm{O}_{2}$ and high- $\mathrm{CO}_{2}$ environments [24], although the actual affinity of RubisCO in the P. okutanii symbiont for $\mathrm{CO}_{2}$ has never been investigated. Water around the siphons has been suggested as the $\mathrm{O}_{2}$ source for Phreagena symbionts [25]. The dissolved oxygen (DO) concentration in the seawater above the clam colony site off Hatsushima Island was reported as $44.4 \mu \mathrm{M}$ [26], whereas the seawater DO concentration routinely reached approximately $300 \mu \mathrm{M}$ in our chemosynthetic aquarium [6] (Table 1). Thus, there was a considerable difference in DO concentration between the natural habitat and our tanks. With regard to $\mathrm{CO}_{2}$, it has been suggested that the environment in the bacteriocytes of Phreagena clams may be buffered by a pool of inorganic carbon [27], and inorganic carbon supplies for symbionts do not limit carbon fixation [25]. Nevertheless, high $\mathrm{CO}_{2}$ concentrations in the sediment in the habitat (Table 1) should probably not be overlooked, given that the inorganic carbon is likely taken up by both the foot and the gills of the clam [28] and that form II RubisCO generally functions in low- $\mathrm{O}_{2}$ and high- $\mathrm{CO}_{2}$ environments [24].

In conclusion, the present study demonstrated the efficiency of our artificial chemosynthetic aquarium system for maintaining the abundance of Phreagena symbionts during a long-term rearing period. Additionally, our artificial chemosynthetic aquarium system may have some positive effects on the survival of the host, at least during the initial period of rearing. Improvements in the handling and care of clams on the ship and during the transportation of the clams to the aquarium likely led to longer survival times. Further improvements such as more stable (and probably higher) sulfide concentrations and more subtle control of $\mathrm{O}_{2}$ and $\mathrm{CO}_{2}$ concentrations for reproducing the habitat environment 
should lead to more appropriate metabolic functions of the symbiont and increase the survival of the clams.

Acknowledgements We are grateful to Ms. Yukiko Hori (the executive director of the Enoshima Aquarium) and Mr. Kazuhisa Hori (the president of the Enoshima Aquarium) for their support of our research. We thank Dr. Yoshihiro Takaki and Ms. Kanae Igawa from JAMSTEC as well as the captains and crews of the R/V Natsushima and ROV Hyper-Dolphin for helping with sample collection, and Drs. Tadashi Maruyama, Kazue Ohishi, Chiaki Kato, and Hiroyuki Imachi from JAMSTEC for valuable comments about this study.

Open Access This article is distributed under the terms of the Creative Commons Attribution 4.0 International License (http://creativecommons.org/licenses/by/4.0/), which permits unrestricted use, distribution, and reproduction in any medium, provided you give appropriate credit to the original author(s) and the source, provide a link to the Creative Commons license, and indicate if changes were made.

\section{References}

1. Fisher CR (1990) Chemoautotrophic and methanotrophic symbioses in marine invertebrates. Rev Aquat Sci 2:399-436

2. Kuwahara H, Yoshida T, Takaki Y, Shimamura S, Nishi S, Harada M, Matsuyama K, Takishita K, Kawato M, Uematsu K, Fujiwara Y, Sato T, Kato C, Kitagawa M, Kato I, Maruyama T (2007) Reduced genome of the thioautotrophic intracellular symbiont in a deep-sea clam, Calyptogena okutanii. Curr Biol 17:881-886

3. Pennec ML, Beninger PG, Herry A (1995) Feeding and digestive adaptations of bivalve molluscs to sulphide-rich habitats. Comp Biochem Physiol A 111:183-189

4. Ikuta T, Igawa K, Tame A, Kuroiwa T, Kuroiwa H, Aoki Y, Takaki Y, Nagai Y, Ozawa G, Yamamoto M, Deguchi R, Fujikura K, Maruyama T, Yoshida T (2016) Surfing the vegetal pole in a small population: extracellular vertical transmission of an 'intracellular' deep-sea clam symbiont. R Soc Open Sci 3

5. Miyake H, Kitada M, Lindsay DJ, Itoh T, Nemoto S, Miwa T (2012) How to keep deep-sea animals. In: Ali M (ed) Diversity of ecosystems. InTech, Rijeka, pp 51-72

6. Ohishi K, Yamamoto M, Tame A, Kusaka C, Nagai Y, Sugimura M, Inoue K, Uematsu K, Yoshida T, Ikuta T, Toyofuku T, Maruyama T (2016) Long-term cultivation of the deep-sea clam Calyptogena okutanii: changes in the abundance of chemoautotrophic symbiont, elemental sulfur, and mucus. Biol Bull 230:257-267

7. Maki JS (2013) Bacterial intracellular sulfur globules: structure and function. J Mol Microb Biotech 23:270-280

8. Vetter RD (1985) Elemental sulfur in the gills of three species of clams containing chemoautotrophic symbiotic bacteria: a possible inorganic energy storage compound. Mar Biol 88:33-42

9. Harada M, Yoshida T, Kuwahara H, Shimamura S, Takaki Y, Kato C, Miwa T, Miyake H, Maruyama T (2009) Expression of genes for sulfur oxidation in the intracellular chemoautotrophic symbiont of the deep-sea bivalve Calyptogena okutanii. Extremophiles 13:895-903

10. Watanabe H, Seo E, Takahashi Y, Yoshida T, Kojima S, Fujikura K, Miyake H (2013) Spatial distribution of sister species of vesicomyid bivalves Calyptogena okutanii and Calyptogena soyoae along an environmental gradient in chemosynthetic biological communities in Japan. J Oceanogr 69:129-134

11. Cullberson C, Pytkowicz RM, Hawley JE (1970) Seawater alkalinity determination by the $\mathrm{pH}$ method. J Mar Res 28:15-21
12. US DOE (1994) Handbook of methods for the analysis of the various parameters of the carbon dioxide system in sea water; version 2. ORNL/CDIAC-74. Carbon Dioxide Information Analysis Center

13. Pierrot D, Lewis E, Wallace DWR (2006) MS excel program developed for CO2 system calculations. ORNL/CDIAC-105a. Carbon Dioxide Information Analysis Center, Oak Ridge

14. Luther GW, Glazer BT, Hohmann L, Popp JI, Taillefert M, Rozan TF, Brendel PJ, Theberge SM, Nuzzio DB (2001) Sulfur speciation monitored in situ with solid state gold amalgam voltammetric microelectrodes: polysulfides as a special case in sediments, microbial mats and hydrothermal vent waters. J Environ Monit 3:61-66

15. Espinosa EP, Tanguy A, Le Panse S, Lallier F, Allam B, Boutet I (2013) Endosymbiotic bacteria in the bivalve Loripes lacteus: localization, characterization and aspects of symbiont regulation. J Exp Mar Biol Ecol 448:327-336

16. Fujinoki M, Koito T, Nemoto S, Kitada M, Yamaguchi Y, Hyodo S, Numanami H, Miyazaki N, Inoue K (2012) Comparison of the amount of thiotrophic symbionts in the deep-sea mussel Bathymodiolus septemdierum under different sulfide levels using fluorescent in situ hybridization. Fish Sci 78:139-146

17. Nakamura Y, Konishi M, Ohishi K, Kusaka C, Tame A, Hatada Y, Fujikura K, Nakazawa M, Fujishima M, Yoshida T, Maruyama T (2013) Mucus glycoproteins selectively secreted from bacteriocytes in gill filaments of the deep-sea clam. Open J Mar Sci 3:167-174

18. Livak KJ, Schmittgen TD (2001) Analysis of relative gene expression data using real-time quantitative PCR and the $2(\mathrm{~T})$ (-Delta Delta C) method. Methods 25:402-408

19. Hongo Y, Ikuta T, Takaki Y, Shimamura S, Shigenobu S, Maruyama T, Yoshida T (2016) Expression of genes involved in the uptake of inorganic carbon in the gill of a deep-sea vesicomyid clam harboring intracellular thioautotrophic bacteria. Gene 585:228-240

20. Dahl C, Prange A (2006) Bacterial sulfur globules: occurrence, structure and metabolism. In: Shively JM (ed) Inclusions in prokaryotes. Springer, Heidelberg, pp 21-51

21. Dahl C, Kredich NM, Deutzmann R, Truper HG (1993) Dissimilatory sulphite reductase from Archaeoglobus fulgidus: physicochemical properties of the enzyme and cloning, sequencing and analysis of the reductase genes. J Gen Microbiol 139:1817-1828

22. Friedrich CG, Rother D, Bardischewsky F, Quentmeier A, Fischer J (2001) Oxidation of reduced inorganic sulfur compounds by bacteria: emergence of a common mechanism? Appl Environ Microbiol 67:2873-2882

23. Grimm F, Dobler N, Dahl C (2010) Regulation of dsr genes encoding proteins responsible for the oxidation of stored sulfur in Allochromatium vinosum. Microbiol Sgm 156:764-773

24. Badger MR, Bek EJ (2008) Multiple Rubisco forms in proteobacteria: their functional significance in relation to $\mathrm{CO}(2)$ acquisition by the CBB cycle. J Exp Bot 59:1525-1541

25. Childress JJ, Fisher CR, Favuzzi JA, Sanders NK (1991) Sulfide and carbon-dioxide uptake by the hydrothermal vent clam, Calyptogena magnifica, and its chemoautotrophic symbionts. Physiol Zool 64:1444-1470

26. Miyake H, Yamamoto H, Kitada M, Ueda I, Okoshi K, Kitamura M, Matsuyama K, Tsuchida S (2005) Attempts to rear the deepsea white clams Calyptogena soyoae and Calyptogena solidissima. Oceanogr Jpn 14:645-651

27. Hongo Y, Nakamura Y, Shimamura S, Takaki Y, Uematsu K, Toyofuku T, Hirayama H, Takai K, Nakazawa M, Maruyama T, Yoshida T (2013) Exclusive localization of carbonic anhydrase in bacteriocytes of the deep-sea clam Calyptogena okutanii with thioautotrophic symbiotic bacteria. J Exp Biol 216:4403-4414 
28. Childress JJ, Fisher CR (1992) The biology of hydrothermal vent animals - physiology, biochemistry, and autotrophic symbioses. Oceanogr Mar Biol 30:337-441

29. Hashimoto J, Ohta S, Fujikura K, Fujiwara Y, Sukizaki S (1995) Life habit of vesicomyid clam, Calyptogena soyoae, and hydrogen sulfide concentration in interstitial waters. J Oceanogr 51:341-350

30. Hattori M, Kanie Y, Oba T, Akimono K (1996) Environmental conditions of carbonates and chemosynthetic animal communities associated with cold seepage zones along the subduction zone in Sagami Bay, central Japan. Fossils 60:13-22 (In Japanese with English abstract and figure legends)

31. Masuzawa T (1996) "Cold seepage" in Sagami Bay. Fossils 60:3240 (In Japanese with English abstract and figure legends)

32. Tsunogai U, Ishibashi J, Wakita H, Gamo T, Masuzawa T, Nakatsuka T, Nojiri Y, Nakamura T (1996) Fresh water seepage and pore water recycling on the seafloor: Sagami Trough subduction zone, Japan. Earth Planet Sci Lett 138:157-168 